\title{
O Gabinete Português de Leitura do Rio de Janeiro e a circulação de livros e leitores (1878-1879)
}

The Gabinete Português de Leitura, in Rio de Janeiro, and the circulation of books and readers (1878-1879) Juliana Maia de QUEIROZ* Universidade Federal do Pará (UFPA) Lueny Amanda Oliveira FRANÇA** Universidade Federal do Pará (UFPA)

RESUMO: Este artigo busca analisar alguns anúncios publicados no Jornal do Comércio do Rio de Janeiro mensalmente com a finalidade de veicular dados sobre a saída e entrada de livros no Gabinete Português de Leitura no final da década de setenta do século XIX, momento em que muitas instituições de leitura estavam consolidadas no território brasileiro e o trânsito de impressos e leitores intensificava-se. Tais dados evidenciam aspectos importantes acerca da circulação de livros e leitores dessa instituição, bem como alguns dos títulos de seu acervo. A partir desse estudo, procuramos investigar melhor o universo da circulação de livros e das práticas de leitura no Rio de Janeiro oitocentista.

PALAVRAS-CHAVE: Século XIX. Circulação de livros. Gabinete Português de Leitura.

ABSTRACT: This article examines advertisements published in Jornal do Comércio, in Rio de Janeiro, and provides data concerning the circulation of books in the Gabinete Português de Leitura, also in Rio, in the 1870s. During this time, a number of public and private libraries were created in Brazil, the circulation of printed materials was intensified, and the number of readers increased. The data presented in this article reveals important information the materials available in the Gabinete Português de Leitura and sheds light on reading practices, as well as book circulation in nineteenth-century Rio de Janeiro.

KEYWORDS: Nineteenth century. Book circulation. Gabinete Português de Leitura.

Durante o século XIX o Rio de Janeiro foi beneficiado com instalações de diversas bibliotecas públicas e particulares, sendo que a primeira delas foi a Biblioteca Real fundada em 1810. De acordo com Nelson Schapochnik (2005), a partir desse momento, vários espaços de leitura surgiram no entorno do território brasileiro e a segunda metade daquele século, especificamente entre os anos de 1861 a 1880,

\footnotetext{
* Professora de Literatura Portuguesa na Universidade Federal do Pará (UFPA) e no Programa de PósGraduação em Letras da UFPA. E-mail: jumaiaque@gmail.com

** Graduada em Letras pela Universidade Federal do Pará (UFPA). E-mail: luenyamanda @ gmail.com
} 
representa a consolidação das bibliotecas e gabinetes de leitura no Brasil, uma vez que foram criados cento e oito instituições de leitura na América Portuguesa.

Naquele período a circulação de livros no Rio de Janeiro era intensa, graças ao consolidado comércio livreiro que se expandiu desde o início daquele século. Nesse contexto, a capital do império concentrava grande parte da população do Brasil e atraía pessoas de outras províncias por ser o local de maior efervescência cultural e política. Além disso, muitos imigrantes aportavam no Rio de Janeiro vindos, por exemplo, de Portugal, França, Itália, Inglaterra etc. Nesse cenário, o centro urbano modernizava-se e a economia progredia em decorrência da comercialização do café.

O processo de urbanização do Rio de Janeiro possibilitou o surgimento de diversas escolas de instrução primária que eram frequentadas por ambos os sexos. Muito embora o índice do analfabetismo fosse elevado, essas instituições foram fundamentais para a formação de uma cultura letrada. O estudo de Nelson Schapochnik (2005) aponta que durante o Oitocentos foram criados trinta e um espaços de leitura no Rio de Janeiro, incluindo bibliotecas públicas e gabinetes de leitura. Esses espaços sociais possuíam expressiva movimentação de leitores, o que pode ser comprovado por meio do exame de jornais que circulavam na corte, uma vez que essas bibliotecas publicavam seus dados acerca das práticas de leitura, tais como a quantidade de livros consultados, os temas de maior interesse do público, o número de frequentadores e os idiomas consultados, além do período visitado.

Ao realizarmos a pesquisa ${ }^{1}$ em torno do Jornal do Comércio, um dos periódicos mais importantes do império, entre 1868 a 1879, localizamos a partir do ano de 1874 números que comprovam a significativa circulação de leitores nesses espaços de leitura, dados esses que eram publicados mensalmente na seção Gazetilha. Esses dados se referem a importantes bibliotecas do Rio de Janeiro como, por exemplo, a Biblioteca Municipal, a Biblioteca Fluminense, a Biblioteca Nacional, a Biblioteca da Corte, a Biblioteca Pública e o Gabinete Português de Leitura. Tais informações são importantes para entendermos melhor as práticas de leitura e a preferência do público leitor do Rio de Janeiro oitocentista.

\footnotetext{
${ }^{1}$ Pesquisa de iniciação científica desenvolvida em torno da presença de romances portugueses em anúncios de livros, textos críticos e prosas de ficção no Jornal do Comércio do Rio de Janeiro oitocentista, financiada pelo CNPq e coordenada pela Prof. ${ }^{a}$ Dr. ${ }^{a}$ Juliana Maia de Queiroz.
} 
Nessa perspectiva, os acervos de bibliotecas passaram a indicar as preferências culturais, as influências literárias e as tendências e importações de livros. Portanto, o estudo dessas fontes permite uma melhor compreensão dos hábitos e representações de camadas letradas da população brasileira e seu processo de transformação. (FERREIRA, 1999, p. 333)

Entre as bibliotecas particulares, destacam-se os gabinetes de leitura. No Brasil, estes surgiram como associações culturais geralmente ligadas a comunidades estrangeiras, como, por exemplo, ingleses, portugueses, alemães, etc. Esses espaços de leitura permitiam a fixação do público em suas bibliotecas, mediante pagamento mensal de uma taxa associativa, o que possibilitava a leitura doméstica. Os gabinetes foram instituições importantes para a circulação de leitura e proporcionaram o acesso a obras de diversos gêneros, em um momento no qual o livro era muito caro no Brasil.

No Rio de Janeiro, o Gabinete Português de Leitura, criado em 1837 com o apoio de imigrantes portugueses, destacava-se pelo seu grande acervo de livros. Durante sua existência, mudou várias vezes o endereço de sua sede, o que ocorria pela rapidez do crescimento de seu acervo. Na década de 1870, esse gabinete contava com mais de quarenta mil volumes. Conforme Ubiratan Machado (2010) explica, essa instituição foi uma das bibliotecas mais frequentadas pelos intelectuais da corte, e era lugar de encontro entre os representantes da cultura letrada do país, a exemplo de Machado de Assis, que devia se deleitar com a leitura dos romancistas portugueses.

O referido gabinete era local de sociabilidade entre os membros da corte, onde se estreitavam relações entre políticos e profissionais de diversos ramos da sociedade oitocentista carioca que se distraíam, inclusive, com os eventos sediados por essa instituição, como nos explica Tânia Bessone Ferreira:

Como espaço de sociabilidade, o Gabinete teria sido responsável pela intensificação de laços afetivos, políticos e profissionais entre seus frequentadores. Foram inúmeros os projetos comuns que permitiram o estreitamento de relações sociais e culturais. Houve ênfase nos cuidados de manutenção do acervo bibliográfico, significativo para médicos, advogados e comerciantes, e na integração de vários projetos culturais luso-brasileiros. Além da sala de leitura, possuía instalações para conferências e outros eventos culturais. Havia programação de centenários de escritores, comemorações ligadas a importantes datas comuns a Portugal e ao Brasil. Foi muito significativa também a colaboração entre seus administradores e associados. (2001, p. 3)

Percebe-se, portanto, a importância desse gabinete de leitura para a cultura letrada oitocentista carioca, pois nele havia heterogeneidade sociocultural dos frequentadores 
que se diversificavam tanto no grau de escolaridade quanto na renda mensal. A pesquisa em torno do Jornal do Comércio nos possibilitou resgatar parte da história da leitura da referida biblioteca; sendo assim, busca-se com este trabalho demonstrar os dados de movimentação de livros e dos frequentadores do Gabinete Português de Leitura, o que nos permite recuperar parte da história cultural do Rio de Janeiro na segunda metade do século XIX, momento em que a circulação de livros e as instalações de bibliotecas estavam em plena expansão no Brasil.

\section{O Gabinete Português de Leitura do Rio de Janeiro: e a movimentação} de livros e leitores

Com o propósito de investigarmos acerca da história da leitura na capital do império, realizamos uma pesquisa documental no Jornal do Comércio, disponível no site da hemeroteca digital e na Biblioteca Nacional, com o objetivo de recuperar dados relativos à presença e circulação de romances portugueses através de anúncios publicados por livreiros estabelecidos no Rio de Janeiro entre os anos de 1868 a 1879.

O trabalho em periódicos requer o exame dessa fonte primária como um todo, ou seja, não só a seção de anúncios deve ser verificada, mas o jornal por completo deve ser examinado. No que se refere ao estudo da história do livro e da leitura no Brasil, a imprensa constitui-se em um valioso objeto de pesquisa. Desse modo, os jornais são fontes preciosas para observamos os processo de circulação de livros no oitocentos brasileiro.

Sendo assim, no decorrer da referida pesquisa, foi identificado, a partir do ano de 1874, na seção Gazetilha, localizada geralmente na primeira ou segunda página do periódico aqui analisado, publicações sobre a movimentação das principais bibliotecas do Rio de Janeiro. Esses dados se referem à quantidade de leitores, obras, idiomas e interesse do público, o que nos permite levantar hipóteses em torno da preferência dos leitores e das práticas de leitura da sociedade carioca no século XIX. A partir do exame dos dados relativos ao Gabinete Português de Leitura, chegamos a algumas conclusões sobre essa importante instituição oitocentista. O seu regulamento, disponível no catálogo de 1858, esclarece as regras de acesso aos livros do acervo de sua biblioteca: era permitida a leitura interna por visitantes, associados e subscritores no horário das oito da manhã às duas da tarde e das quatro da tarde às nove da noite, mas aos domingos 
e dias santos o espaço permanecia aberto apenas até o meio dia. Em feriados como o Natal, o domingo da Páscoa e Corpus Christi, o gabinete não era aberto ao público. Isso nos permite observar que esse estabelecimento era muito flexível em relação ao horário de funcionamento, pois possibilitava que diversos ramos da sociedade pudessem frequentar seu espaço em dois turnos do dia, abrindo assim mais possibilidades de acesso a seu acervo.

De acordo com o regulamento desse gabinete era também proibido manipular os livros nas estantes. Desse modo, os leitores deveriam pedir as obras desejadas. Infere-se, então, que o catálogo de livros era fundamental para o conhecimento e a escolha das obras presentes nas prateleiras, bem como para requerimento de leitura interna. Havia também a advertência referente à impossibilidade de leitura externa de dicionários, atlas, mapas, periódicos, obras raras e livros em brochura, todos impedidos de sair do estabelecimento.

A leitura externa era permitida somente aos associados e subscritores mediante pagamento de taxa, sendo que tal renda destinava-se provavelmente também à manutenção do estabelecimento e pagamentos de funcionários. O empréstimo de livros era registrado em um livro de saída, o que possibilitava a leitura doméstica, desse modo, contribuindo para leitura em gabinetes particulares e em voz alta. Assim, outras pessoas que pertencessem ao círculo do associado teriam acesso às obras do acervo. $\mathrm{O}$ tempo máximo que essas pessoas poderiam ter posse dos livros variava entre quinze e trinta dias. As obras adquiridas por meio de compra, oferta dos assinantes e devolução eram anotadas no livro de entrada.

A movimentação de obras e frequentadores do Gabinete Português de Leitura foram localizados no Jornal do Comércio a partir do segundo semestre de 1878, período em que verificamos a presença de dados sobre a frequência de leitores, idiomas dos livros consultados, oferta de livros, e saída e entrada de volumes desse gabinete. No que se refere ao ano de 1879, oito meses foram localizados, enquanto que outros não foram registrados por não haver publicação desses dados. No entanto, isso não diminui a relevância dos presentes resultados que resgatam informações sobre a circulação de leitores em uma das bibliotecas mais importantes do Rio de Janeiro oitocentista. Sendo assim, vejamos as tabelas abaixo com os dados de circulação de livros e leitores do Gabinete Português dos anos de 1878 e 1879: 


\begin{tabular}{|l|c|l|l|c|c|c|}
\hline \multicolumn{7}{|c|}{ ANO 1878 } \\
\hline Mês & $\begin{array}{l}\text { Saída de } \\
\text { volumes }\end{array}$ & $\begin{array}{l}\text { Entrada } \\
\text { de } \\
\text { volumes }\end{array}$ & Total & Leitores & Visitantes & Total \\
\hline Julho & SIE & SIE & 3595 & 246 & 17 & 263 \\
\hline Agosto & SIE & SIE & 3674 & 266 & 19 & 285 \\
\hline Setembro & 1750 & 1848 & 3598 & 255 & 7 & 262 \\
\hline Outubro & 1925 & 1913 & 3838 & 249 & 15 & 264 \\
\hline Novembro & 1860 & 1813 & 3663 & 271 & 14 & 285 \\
\hline Dezembro & 1998 & 1993 & 3991 & 253 & 18 & 271 \\
\hline Total & $\mathbf{7 5 3 3}$ & $\mathbf{7 5 6 7}$ & $\mathbf{2 2 3 5 9}$ & $\mathbf{1 5 4 0}$ & $\mathbf{9 0}$ & $\mathbf{1 6 3 0}$ \\
\hline
\end{tabular}

SIE: Sem informação específica; Fonte: Jornal do Comércio.

Os presentes resultados demonstram a intensa circulação de livros no Gabinete

\begin{tabular}{|l|c|c|c|c|c|c|}
\hline \multicolumn{7}{|c|}{ ANO 1879 } \\
\hline Mês & $\begin{array}{c}\text { Saída de } \\
\text { volumes }\end{array}$ & $\begin{array}{c}\text { Entrada de } \\
\text { volumes }\end{array}$ & Total & $\begin{array}{c}\text { Leitore } \\
\text { s }\end{array}$ & $\begin{array}{c}\text { Visitante } \\
\text { s }\end{array}$ & Total \\
\hline Janeiro & 1727 & 1801 & 3528 & 250 & 20 & 270 \\
\hline Fevereiro & 1643 & 1620 & 3263 & 231 & 12 & 243 \\
\hline Junho & 1767 & 1759 & 3526 & 237 & 13 & 250 \\
\hline Julho & SIE & SIE & 3545 & 223 & 16 & 239 \\
\hline Setembro & 1889 & 1867 & 3756 & 263 & 10 & 273 \\
\hline Outubro & 1823 & 1759 & 3582 & 267 & 16 & 283 \\
\hline Novembro & 1748 & 1772 & 3520 & 264 & 15 & 279 \\
\hline Dezembro & 1920 & 1844 & 3774 & 264 & 10 & 274 \\
\hline \multicolumn{1}{|c|}{ Total } & $\mathbf{1 2 5 1 7}$ & $\mathbf{1 2 4 2 2}$ & $\mathbf{2 8 4 9 4}$ & $\mathbf{1 9 9 9}$ & $\mathbf{1 1 2}$ & $\mathbf{2 1 1 1}$ \\
\hline
\end{tabular}

Português de Leitura, movimentando no mínimo três mil livros mensalmente. Se compararmos as tabelas, veremos que o trânsito de livros quase dobrou no ano de 1879 , o que nos dá indícios do aumento do interesse do público. Não esqueçamos que alguns meses não estão disponíveis, por isso, acreditamos que os números seriam bem maiores se tivéssemos acesso a todos os dados.

Vejamos a seguir algumas imagens publicadas no Jornal do Comércio em diferentes edições: 
IMAGEM 1

Bibllothees de Gabluete Portagaez do Kel. turn - 0 movizest, Laraste o mer de Seterobin fiodo foi de 3,756 vilames, sento 1,889 sabidute 1,867 eqtrados ars neguistes ilicasas: porteggez 3,35t, Irascez 397, hospabol 5, inglez 1 ifuliano 1.

A bibliotheca $f$ i frequentais por 263 leitores e 10 visituntes, e recebra 7 volames cffertalos, eitando cospribealido neste su nero a m graifica eliçis portazuers do D. Quixote de la Maneia, publiesda pela compashia litteraria do Porto, eflerta do Sr. Job́o de Sonas Ciras.

Jornal do Comércio, edição de 03/10/1879.

IMAGEM 2

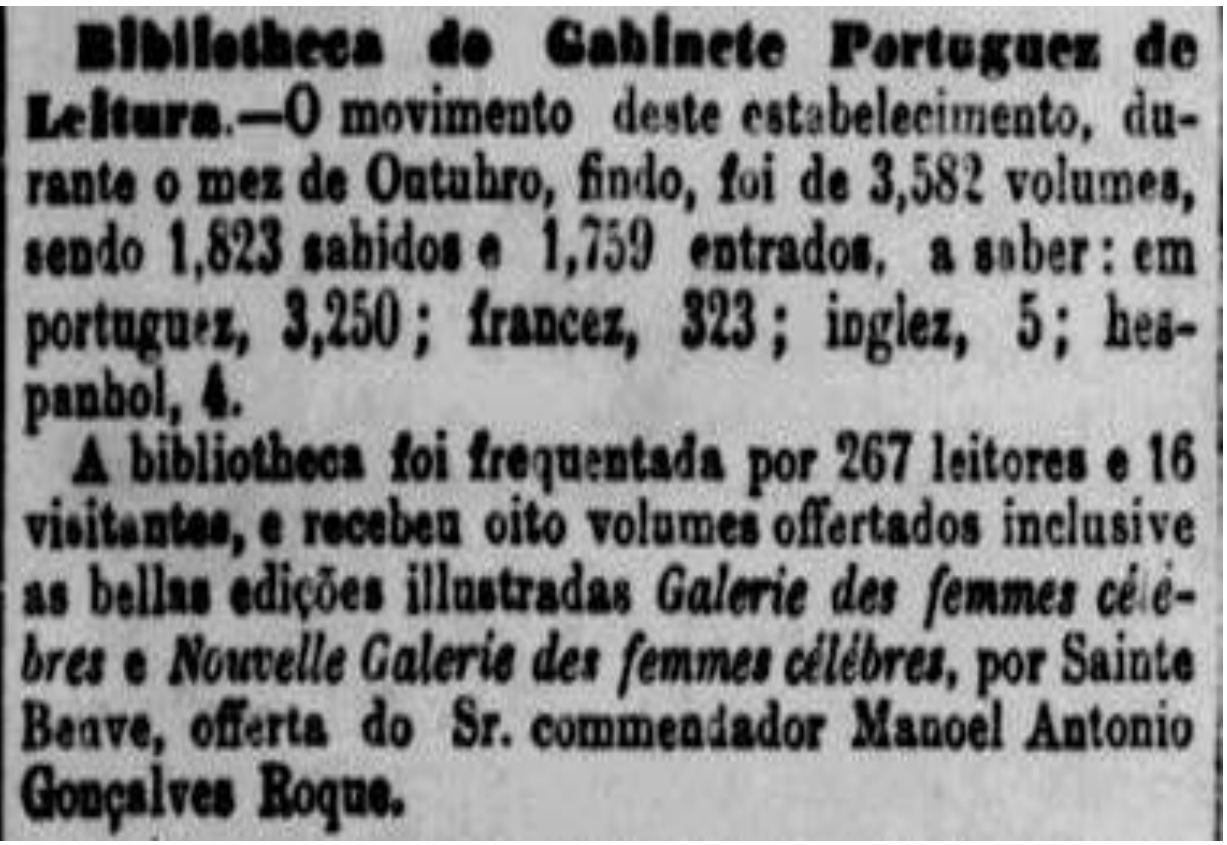

Jornal do Comércio, edição de 04/11/1879. 


\section{IMAGEM 3}

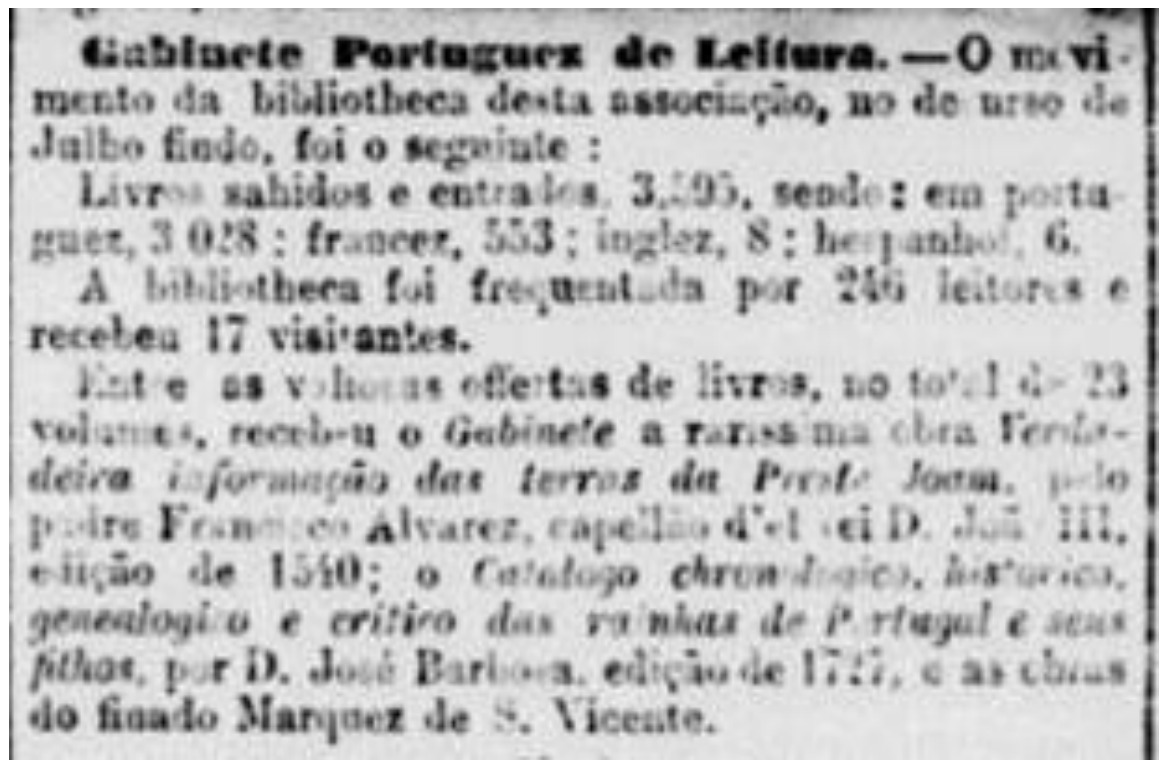

Jornal do Comércio, edição de 04/08/1878.

Essas informações são valiosas, pois por meio delas conseguimos conhecer alguns títulos que faziam parte do acervo, gêneros das obras, ano da edição e perfil dos associados. Desta forma, adentramos no universo por vezes bastante nebuloso que é aquele de tentar alcançar aspectos relativos ao gosto do público do período oitocentista no Brasil. Nessas imagens, chama-nos atenção, por exemplo, a variedade dos gêneros ofertados que pertenciam a autores e obras consagradas, como Dom Quixote de La Mancha, de Miguel de Cervantes, assim como edições ilustradas em língua estrangeira: Galerie des femmes célèbres e Nouvelle galerie des femmes célèbres. Obras raras também eram doadas ao gabinete, como pode ser conferido na imagem três com menção a obras dos anos de 1540 e 1727. No decorrer da pesquisa com o Jornal do Comércio, notamos que há meses sem informações sobre livros ofertados, sendo que a maior quantidade catalogada foi o mês de dezembro de 1879 com cento e quatro livros doados de diversos gêneros.

Além da circulação de livros e do movimento dos frequentadores, eram divulgados os números relativos aos idiomas das obras que saíam e entravam no 
Gabinete Português de Leitura. Na tabela abaixo, estão expressos os dados com os idiomas consumidos pelos leitores do Gabinete Português de Leitura, entre os anos de 1878 a 1879:

\begin{tabular}{|l|l|}
\hline \multicolumn{2}{|c|}{ ANOS 1878-1879 } \\
\hline IDIOMA & TOTAL \\
\hline Português & 44.010 \\
\hline Francês & 6.463 \\
\hline Latim & 07 \\
\hline Espanhol & 79 \\
\hline Inglês & 66 \\
\hline Italiano & 07 \\
\hline
\end{tabular}

Fonte: Jornal do Comércio, anos de 1878 e 1879.

Os presentes dados nos revelam que nesse espaço de estudo e erudição havia leitores poliglotas e que tinham interesse tanto por obras em língua portuguesa quanto por obras estrangeiras. A tabela indica também que o latim, embora não houvesse muitos adeptos desse idioma nesse período, ainda atraía leitores. Os números demonstram ainda a expressiva quantidade de obras em francês, mas o português foi o idioma mais lido naquele período. Isso não significa que os leitores tinham preferência superior por obras brasileiras e portuguesas, pois sabemos que, assim como na Europa oitocentista, havia muitas traduções em circulação na capital do império.

\section{Considerações finais}

Embora nesse período o analfabetismo no Rio de Janeiro fosse bastante considerável, os dados aqui apresentados comprovam a existência significativa de uma cultura letrada na capital do império. O gabinete aqui estudado foi uma instituição importante para assegurar aos leitores cariocas o acesso a livros com os mais variados títulos, incluindo muitos romances, o gênero que tanto agradou leitores oitocentistas no Brasil e na Europa. Os gabinetes de leitura marcaram a vida intelectual carioca e foram fundamentais para a valorização da leitura e a circulação de livros no Rio de Janeiro. O Gabinete Português de Leitura foi também um importante espaço de sociabilidade, estudo e erudição no qual se podia deleitar tanto da leitura individual e silenciosa quanto da leitura doméstica. Os presentes dados ratificam estudos mais recentes que 
evidenciam o quanto no Rio de Janeiro havia um público leitor que tinha predileção por obras tanto nacionais quanto estrangeiras, muitas vezes traduzidas do francês.

A partir da rotina de funcionamento e frequência dos leitores, percebe-se que esse gabinete não se limitava aos integrantes da elite social e econômica, em razão de receber associados e visitantes das mais variadas camadas da sociedade em seu estabelecimento. Portanto, por meio dessa pesquisa, foi possível escrever um pequeno capítulo a mais acerca da história que ainda está sendo contada em torno da circulação de livros e leitores no Rio de Janeiro na segunda metade do século XIX.

\section{REFERÊNCIAS}

ABREU, M.; SCHAPOCHNIK, N. (Orgs.). Cultura letrada no Brasil: objetos e práticas. Campinas: Mercado de Letras, 2005.

CATÁloGO: Gabinete Português de Leitura do Rio de Janeiro. Rio de Janeiro: Tipografia Comercial de F. de. O. Q. Regadas, 1858.

FERREIRA, T. M. T. B. C. Bibliotecas de médicos e advogados do Rio de Janeiro: dever e lazer em um só lugar. In: ABREU, M. (Org.). Leitura, história e história da leitura. Campinas: Mercado de Letras, 1999.

As bibliotecas públicas cariocas no século XIX. In: XXIV Congresso Brasileiro da Comunicação INTERCOM, 2001, Campo Grande. Anais: Sociedade Brasileira de Estudos Interdisciplinares da Comunicação. Campo Grande: INTERCOM, 2001. MACHADO, U. A vida literária no Brasil durante o Romantismo. $2^{\mathrm{a}}$. ed. Rio de Janeiro: Tinta Negra, 2010. 